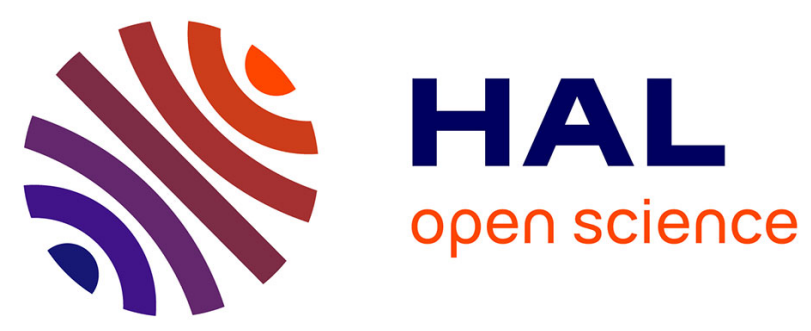

\title{
Delivering to Urban Online Shoppers: The Gains from "Last-Mile" Pooling
}

Bruno Durand, Sonia Mahjoub, Marie-Pascale Senkel

\section{To cite this version:}

Bruno Durand, Sonia Mahjoub, Marie-Pascale Senkel. Delivering to Urban Online Shoppers: The Gains from "Last-Mile" Pooling. Supply Chain Forum: An International Journal, 2013, 14, pp.4 2013. hal-01766913

\section{HAL Id: hal-01766913 https://hal.parisnanterre.fr/hal-01766913}

Submitted on 17 Apr 2018

HAL is a multi-disciplinary open access archive for the deposit and dissemination of scientific research documents, whether they are published or not. The documents may come from teaching and research institutions in France or abroad, or from public or private research centers.
L'archive ouverte pluridisciplinaire HAL, est destinée au dépôt et à la diffusion de documents scientifiques de niveau recherche, publiés ou non, émanant des établissements d'enseignement et de recherche français ou étrangers, des laboratoires publics ou privés. 


\section{Delivering to Urban Online Shoppers: The Gains from "Last-Mile" Pooling}

Bruno Durand

University of Nantes LEMNA, France

bruno.durand@univ-nantes.fr

Sonia Mahjoub

Ecole Nationale Vétérinaire, Agroalimentaire et de I'Alimentation ONIRIS, France sonia.el-mahjoub@oniris-nantes.fr

Marie-Pascale Senkel University of Nantes LEMNA, France marie-pascale.senkel@univ-nantes.fr

In an era when B2C is developing at a steady pace, it is essential to be concerned with the ramifications of delivering to urban online shoppers, whether the goal is home delivery of goods ordered online or delivery to a nearby pickup point. This article aims to examine this problem, restricting itself to non-food items. With cooperation enabling the obstacle of the "last mile" to be overcome, the emphasis is clearly on the concept of logistic pooling. In more practical terms, we will present three scenarios of delivering to urban online shoppers. We will then analyse these scenarios using accurate simulations, with a view to measuring their respective performance levels, economically as well as ecologically speaking.

Key words: city logistics, pooling, home delivery (HD), delivery to a nearby pickup point (NPP), local delivery depot (LDD)

\section{Introduction}

The transport of goods in urban areas has long been subjected to twofold ignorance: politically and scientifically (Patier, 2002). Not until the 1970s did public authorities start drawing up the first urban mobility plans (Dufour \& Patier, 1997), in effect the first regulations governing the transport of merchandise within towns. This progressive and collective awareness bore in mind that, within an urban area and its suburbs, the transport of goods for delivery and collection takes up about $30 \%$ of road space. With the revival of retail outlets in town centres it is now more important than ever to avoid all road congestion and pollution (atmospheric and noise). Experts at Centre d'Etudes sur les Réseaux, les Transports, l'Urbanisme et les Constructions Publiques (Centre for Studies on
Networks, Transportation, Urbanism and Public Buildings) suggest this be achieved through controlling vehicle movements, particularly when deliveries are involved (Thévenon, 2011).

At a time when B2C e-commerce is developing at a steady rate (about 15\% increase in France in 2013, according to the French Fédération du E-commerce et de la Vente à Distance [Federation for ECommerce and Distance Selling]), it is impossible to remain indifferent to its impact on logistics. The problems raised by delivering to urban online shoppers should therefore be of primary concern. The upheaval is sizeable, because B2C sales involve either direct home delivery (HD) of the products purchased online or delivery to a nearby pickup point (DPP). These seemingly straightforward practices are, in reality, not that simple, especially when towns 
already suffer from traffic congestion. The development of ecommerce has therefore made traditional transport practices extremely more complex and has given rise to new methods as well as to the appearance of new logistics service providers (LSP). Indeed, it is a question of an entirely new logistics, more diffuse and widespread (as opposed to mass logistics in the case of $\mathrm{B} 2 \mathrm{~B}$ ). This new logistics has been dubbed e-logistics or net-logistics.

There are currently 34 million online consumers in France, and as a result, about 34 million homes to deliver to (representing more or less the total number of households in France). Even if this number remains constant, the number of parcels to be delivered to private individuals (more than 600 million in 2013 and more than likely more than 700 million in 2014) will continue to increase at a significant rate and should soon reach several units delivered per month or even per week. We must not lose sight of the fact, however, that the average number of purchases by online consumers is currently only 16 per annum (compared to 7 per annum in 2006). Urban logistics could therefore, in the immediate future, be a key factor in the growth - or indeed the failure - of online sales because delivering increasing numbers of parcels to urban households is in danger of becoming more and more complicated unless current distribution models are called into question. We could be tempted to note that the issue of urban distribution has already been partially resolved insomuch as e-logistics have improved considerably. This would be speaking too soon, however, because although systems are in place for HD and DPP, we can question whether or not they are sufficient to be able to really cope with the increased demands of tomorrow's online shoppers. Can the current logistics model guarantee a steady growth of B2C and at the same time develop a longer perspective of sustainable development, particularly in ecological and economic terms?
It is for this reason we wish to mainly concentrate in this article on the issue of distribution to urban online shoppers and to limit our research to non-food items. Our research, carried out in particular through LSP, has enabled us to clearly define the different ways of overcoming the obstacles inherent in delivering parcels to individual households. In the face of the recurrent problems towns come across in their logistics management, we are more and more convinced that cooperation among all those involved can overcome the obstacle of the "last mile". Moreover, this is why, along the way, we are interested in the concept of logistics pooling. The specific aim of our article is to present scenarios showing the changes in urban domestic distribution and to demonstrate

\section{There are currently}

\section{4 million online}

\section{consumers in France,}

$$
\text { and as a result, }
$$

\section{about 34 million}

\section{homes to deliver to.}

that pooling of physical flows represents a real logistical performance vector, from as much an economic as ecological point of view. Through our different lines of investigation, generally through direct discussions with experts, we have been able to identify three key development scenarios: (1) "0pooling"; (2) partial pooling through nearby pickup points; and (3) pooling via a local delivery depot, guaranteeing an "all-in-one" solution with either a single home delivery or collection.

\section{The "0-pooling" scenario}

In this first scenario, delivery companies, and in particular parcel services and express delivery services, look to improve their level of performance by trying to reduce the rate of failure to deliver to online shoppers (FDOS) or by reducing $\mathrm{CO} 2$ emissions during a delivery round. It should be stressed that any attempts at improvement are done on a purely independent basis, that is, "every person for him- or herself". There is no noticeable intragroup cooperation nor, indeed, between competitors. Some operators tend towards greater use of technology (managing the delivery rounds in real time to avoid wasted stops). Others opt for use of more compact, cleaner vehicles (for example, by changing part of their fleet to electric). It can be added that urban parcel delivery services are rarely just $\mathrm{B} 2 \mathrm{C}$ : they generally consist of a mix of both $\mathrm{B} 2 \mathrm{C}$ and $\mathrm{B} 2 \mathrm{~B}$. This subsequently reduces productivity of these mixed rounds compared to those purely dedicated to $\mathrm{B} 2 \mathrm{C}$. Because it is practically impossible to increase the time of a delivery round, the tendency is for the quantity of parcels delivered per round to decrease. This is for the simple reason that the average number of parcels delivered to door is noticeably decreasing. There is generally just one item delivered in $\mathrm{B} 2 \mathrm{C}$, whereas the number of households to deliver per round is on the increase.

The key aim concerning $\mathrm{B} 2 \mathrm{C}$ is to reduce the rate of failure to deliver first time to online shoppers. According to operators, this failure rate stands currently between $10 \%$ and $40 \%$ of total households to be delivered. More specifically the aim would be to reduce that figure to zero. That means successfully delivering to all online shoppers at the first attempt, which represents a huge challenge. Some LSP are already achieving this by delivering to customers only when they are sure to be able to, generally following a confirmation phone call. The aim is to not incur unnecessary kilometres when a customer is not at home, nor add supplementary kilometres associated with redeliveries. This then improves time efficiency because delivery rounds are shorter. Noise pollution and 
atmospheric pollution - through fewer greenhouse gas emissions are also reduced.

Various solutions are recommended (Patier, 2009), in particular more dynamic operation techniques, which combine established information about the customer during the delivery round, for example, absence due to unforeseen circumstances or lateness when presence for the delivery is essential. Obviously this type of dynamic delivery management is possible only if the online consumer gives updates as to his or her availability. Only then can dynamic delivery management lead to a reduction in operating costs and greenhouse gas emissions. We should underline that such undertakings tend to be on an individual basis and devoid of any intention to cooperate intragroup in the long term, particularly through flows pooling. The emphasis seems to be on developing quickly and innovating before the competition does in order to gain a clear competitive edge. Under these circumstances, the performance level of urban logistics, whilst improving in terms of economic and ecological impacts, remains too modest to lead to a significant reduction in pollution caused by transport of goods in urban areas.
In order to accurately evaluate performance levels in the distribution of parcels to households, we carried out 15 expert interviews in Nantes and Rennes town centres and suburbs with the most important operators in home delivery services (La Poste Group, DHL, Géodis, Schenker, Dachser, Deret, Colis Privé, Girard Agediss). These interviews were constructed around two key subjects: (1) their experiences of pooling in $\mathrm{B} 2 \mathrm{C}$ and (2) the economic and environmental results of these experiences. These interviews were often followed up by in situ observations to enable us to better visualise the physical and informational constraints associated with managing the final delivery. We were therefore able to check that these e-LSP (La Poste and the main parcel and express delivery companies) are in direct competition when it comes to HD. That is, that each company relies on its own network. There is no collaboration at all among the different operators. We refer to this as "no pooling" or "0-pooling". All delivery rounds are separate, which means that the same online shopper (or even retailer) can be disturbed several times in the same day or evening by different delivery companies. Looking at Figure 1 this can be seen to affect in particular customer 4 (or retailer $\mathrm{C}+2$ ).
If the Internet customer is not at home to receive a delivery, has a non-standard letterbox (in particular too small), or if a signature is essential, then this is in effect a failure to deliver. At La Poste Group, the level of failure that they refer to as "delivery pending" is in the region of $10 \%$ to $15 \%$ of total online shoppers to be delivered, which seems reasonable. However, for some express delivery services, this rate can be close to $40 \%$ (see Box 1). We can add, however, that the various expert interviews carried out have revealed the main reason for failure to deliver to be poor quality of information. Indeed, in $50 \%$ of cases, the failure of a home delivery is more likely to be because of having the wrong or incomplete address, no telephone number or email address or these being wrong, or no entry code to a secure residence, rather than the customer not being there.

We can consider the first scenario of deliveries to urban households as a reference model insomuch as this was what was used in the early days of B2C. If we look even closer at deliveries to online shoppers in the hyper-centre of Nantes, using this model the operating costs have been calculated at 5,750€ net per day. On the environmental level, $\mathrm{CO}_{2}$ emissions have been evaluated

Figure 1

Scenario of HD to urban online shoppers with no load pooling among rival operators

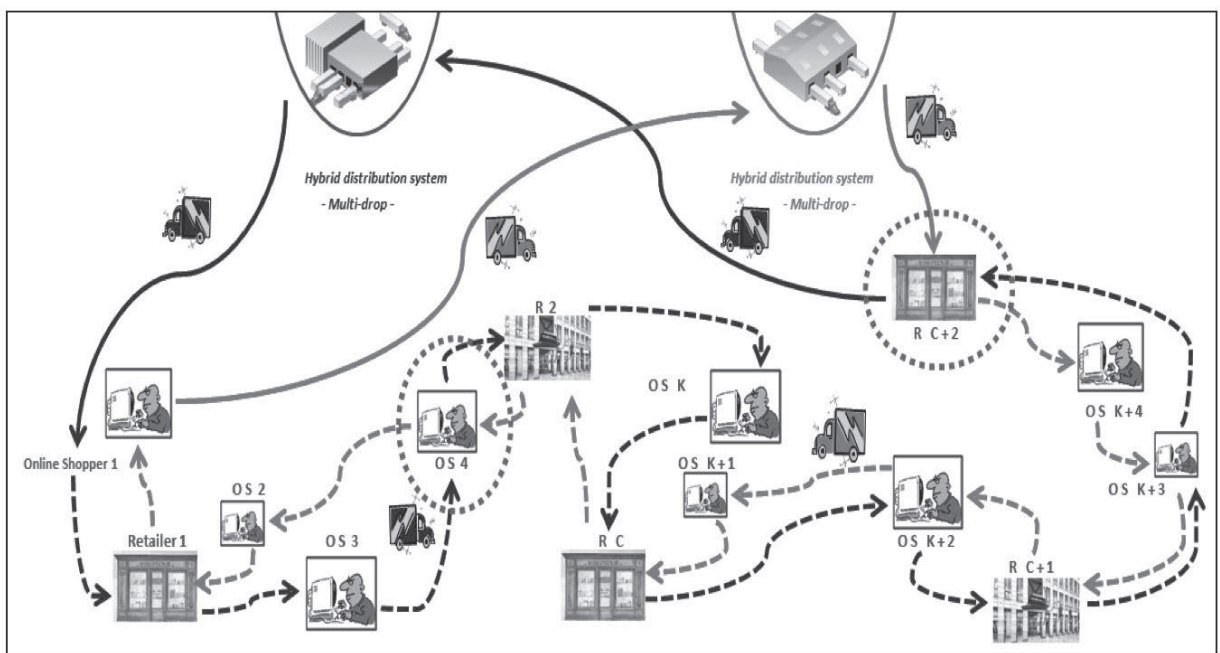


Box 1:

"0-pooling" of deliveries to online shoppers in Nantes

Every day, around 907 online shoppers in the hyper-centre of Nantes receive a home delivery. At an average of 1.1 parcels per delivery, this gives a total of 998 parcels to deliver. To enable this, about 10 logistics operators (postal, parcel, and express services) operate around 23 mixed delivery rounds (households and retailers):

- The main operator (postal) alone delivers 648 parcels (65\% of the total) using nine delivery rounds. For each of these rounds, $90 \%$ of parcels are for households with an average of 65 deliveries to online shopper, making a total of 72 addresses at a rate of nine per hour.

- The other "parcel" or "express" operators deliver the remaining 350 parcels by way of 14 delivery rounds. Of these parcels $75 \%$ are for retailers with an average of 23 deliveries to online shoppers, making a total of 48 addresses at a rate of six per hour.

These operators deliver to the town from branches situated on average $15 \mathrm{~km}$ away from the very centre. The average length of a delivery round is $45 \mathrm{~km}$ : $30 \mathrm{~km}$ outbound and $15 \mathrm{~km}$ actually carrying out deliveries. The average operating cost of a delivery round is estimated at $250 €$ net.

Two-thirds of vehicles used by postal operators are diesel or petrol powered, in the LCV category (light commercial vehicles), with $\mathrm{CO}_{2}$ emissions of $0.3194 \mathrm{~kg}$ per $\mathrm{km}$. The remainders are electric $\mathrm{LCV}$ with $\mathrm{CO}_{2}$ emissions of $0.05 \mathrm{~kg}$ per $\mathrm{km}$. As for parcel and express services, $72 \%$ of the vehicles used are petrol or diesel powered, six 10T trucks with $\mathrm{CO}_{2}$ emissions of $0.5324 \mathrm{~kg}$ per $\mathrm{km}$, and four LCV with $0.3194 \mathrm{~kg}$ emissions per $\mathrm{km}$. Four of the 14 delivery rounds are also carried out using electric LCV with $\mathrm{CO}_{2}$ emissions of $0.05 \mathrm{~kg}$ per $\mathrm{km}$.

The concept of failure to deliver first time to retailers is non-existent but generally greater than $10 \%$ for home online shoppers: $5 \%$ to $14 \%$ for postal service deliveries; 13 to $40 \%$ for parcel and express service deliveries.

Table 1

Economic and ecological impacts of failure to deliver first time, with $100 \%$ HD

\begin{tabular}{|c|c|c|c|c|}
\hline Rate of failure to deliver 1st time to online shopper & Simul 1 & Simul 2 & Simul 3 & Simul 4 \\
\hline - 9 "postal" service rounds & $14 \%$ & $11 \%$ & $8 \%$ & $5 \%$ \\
\hline - 14 parcel service rounds & $40 \%$ & $31 \%$ & $22 \%$ & $13 \%$ \\
\hline Total of Failure to Deliver to Online Shoppers (FDOS) & 207 & 161 & 115 & 78 \\
\hline Percentage of FDOS & $23 \%$ & $18 \%$ & $13 \%$ & $9 \%$ \\
\hline Total cost of FDOS & $937 €$ & $729 €$ & $521 €$ & $344 €$ \\
\hline Total CO2 emissions (Kg) from FDOS & 51.0 & 39.6 & 28.4 & 18.3 \\
\hline Percentage of $\mathrm{CO} 2$ emissions from FDOS to total emissions & $17 \%$ & $13 \%$ & $9 \%$ & $6 \%$ \\
\hline
\end{tabular}

at just over $300 \mathrm{~kg}$ per day. During our research into the first scenario, our main interest was in calculating, through a series of simulations, the impact of a failure to deliver first time on the following levels: (1) economic, by evaluating the cost of that failure to deliver to online shoppers, and (2) ecological, by calculating the $\mathrm{CO}_{2}$ emissions attributable to this failure to deliver to online shoppers. Table 1 gives a summary of findings using four particularly pertinent simulations. We must draw attention to the impact on cost and $\mathrm{CO}_{2}$ emissions as a result of reduction in the rate of failure to deliver, and therefore better quality of information, notably between simulation 1 (23\% not delivered) and simulation 4 (9\% not delivered). The totals for both have been divided by three.

\section{The scenario of pooling via nearby pickup points}

In the second scenario, that of partial pooling via nearby pickup points (NPP), parcels are picked up directly by the consumer at local retail outlets. This option bypasses the tricky problem associated with HD: that of absent customers when there is a need for their presence, for example, to accept an oversized parcel or sign for a delivery. This way there is no failure to deliver because the parcel is deposited at a local retail unit, which effectively doubles as an NPP insomuch as it is situated in an area already frequented by the online shopper and that opening hours are fairly long. Today in France, there are a handful of structured NPP operators with four very competitive and close-knit networks, all with around 5,000 NPP. Some of them, such as Relais Colis (La Redoute group) and Mondial Relay (3 Suisses group), came about as a result of mail-order sales. Others, such as Kiala and Pickup Services (La Poste group) have appeared over the course of the last 10 years.

Through these networks of NPP we have touched on a first type of pooling, insomuch as a NPP is not just dedicated to one online shopper compared to a letterbox at home. It is shared by online shoppers living in the same area. We must quickly emphasize, however, that there is still no consolidation among the different logistics operators of NPP networks. The situation is quite the 
opposite, which means that the same online shopper, for example customer 3 in Figure 2, may have to visit several NPP used by rival networks depending on what has been ordered online and the logistics agreements signed between online retailers and the NPP networks. This could mean a trip to an NPP, then to a Kiala point, followed by another to a Mondial Relay or Relais Colis point. Thankfully, the close proximity of these locations, only several hundred metres from the online shopper's home, means the trip can be done using relatively "clean" methods of transport, such as on foot or by bicycle. The incentive for Internet consumers to use such practices, which has come about as a result of organisational innovation, contributes a priori to the improvement in the performance level of deliveries to urban households: (1) from an economical viewpoint through a reduction in operating costs as a result of there being no failure to deliver (or any parcels waiting to be dispatched) and (2) from an environmental viewpoint as a result of reduction in $\mathrm{CO} 2$ emissions. This is because online shoppers make their own way to NPP, using no unnecessary or extra kilometres, via methods of transport that result in little or no pollution.

Of course, the scenario of all deliveries to online shoppers through NPP does not exist. They are not exclusively carried out through these locations. However, delivery via NPP, which is the preferred solution for $51 \%$ of the French public (according to a survey by Ifop-Generix [2012]), coexists with $\mathrm{HD}$, which in turn is favoured by $85 \%$ of online buyers in
France. As a result of this, the second scenario is mixed. Furthermore, within the scope of simulations carried out in Nantes centre and suburbs, we sought to vary the proportion of online shoppers delivered to via NPP, from between 0 (refer to scenario 1) and $35 \%$, which is close to the current tendency. Table 2 gives a global illustration of economic and ecological impacts of deliveries via NPP.

We cannot help but notice that the impact of this use of NPP is very positive on two levels. There is a reduction in operating costs of $26 \%$ between the first and last scenarios as well as a $30 \%$ reduction in $\mathrm{CO} 2$ emissions. Use of NPP has also resulted in a noticeable increase in the average number of parcels delivered per stop (15 parcels on average per NPP), which in turn

\section{Figure 2 \\ Scenario of deliveries to urban online shoppers through NPP, with no pooling among rival transporters}

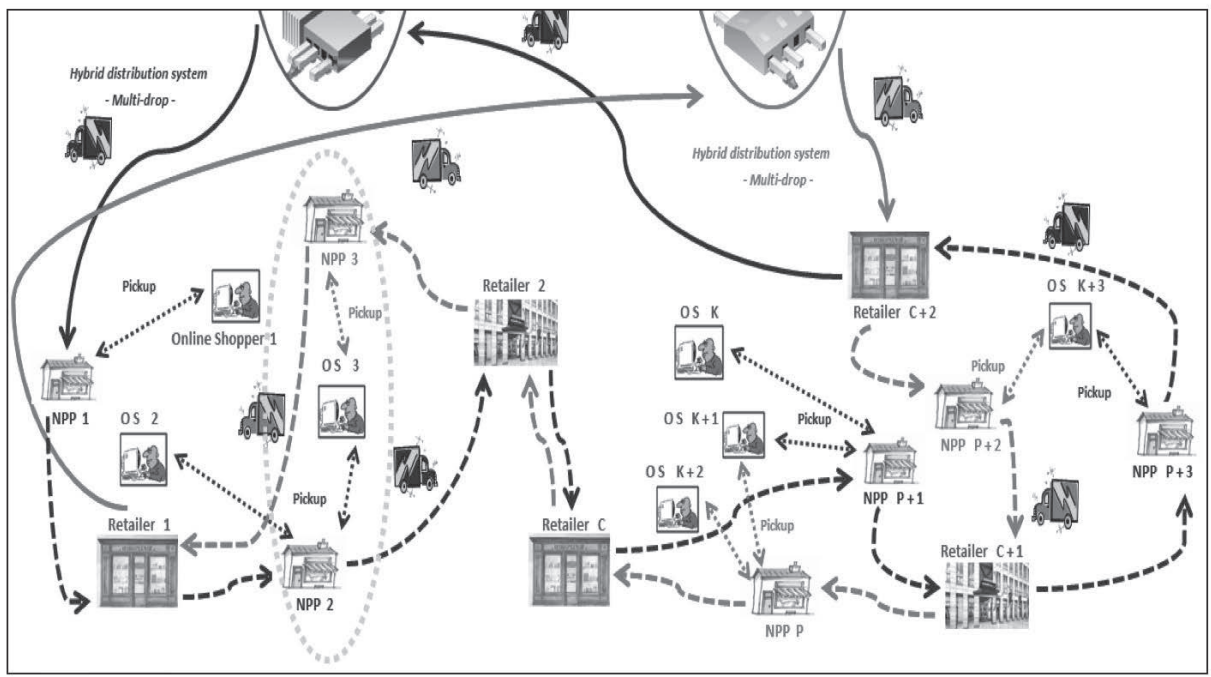

Table 2

Economic and ecological impacts of deliveries via NPP

\begin{tabular}{|l|c|c|c|c|c|c|c|}
\cline { 2 - 8 } \multicolumn{1}{c|}{} & $\begin{array}{c}\text { Number of } \\
\text { HDs to Online } \\
\text { Shoppers }\end{array}$ & $\begin{array}{c}\text { Nb of Online } \\
\text { Shoppers } \\
\text { using NPP }\end{array}$ & $\begin{array}{c}\text { Nb of Urban } \\
\text { Delivery } \\
\text { Rounds }\end{array}$ & $\begin{array}{c}\text { Total } \\
\text { Operating } \\
\text { Costs }\end{array}$ & Difference & $\begin{array}{c}\text { CO2 } \\
\text { Emissions } \\
(\mathrm{Kg})\end{array}$ & Difference \\
\hline Scenario "100\% HD" & 907 & 0 & 23 & $5,750 €$ & & 303 & \\
\hline Mixed scenario "85\% HD" & 769 & 138 & 21 & $5,158 €$ & $-10 \%$ & 282 & $-7 \%$ \\
\hline Mixed scenario "75\% HD" & 677 & 230 & 19 & $4,714 €$ & $-18 \%$ & 254 & $-16 \%$ \\
\hline Mixed scenario "65\% HD" & 585 & 322 & 17 & $4,258 €$ & $-26 \%$ & 213 & $-30 \%$ \\
\hline
\end{tabular}




\begin{tabular}{|c|c|c|c|c|}
\hline Rate of failure to deliver 1st time to online shopper & Simul 1 & Simul 2 & Simul 3 & Simul 4 \\
\hline - 9 "postal" service rounds & $14 \%$ & $11 \%$ & $8 \%$ & $5 \%$ \\
\hline-4 parcel service rounds & $40 \%$ & $31 \%$ & $22 \%$ & $13 \%$ \\
\hline \multicolumn{5}{|l|}{ - 6 "retailers \& NPP" service rounds } \\
\hline Total of Failure to Deliver to Online Shoppers (FDOS) & 117 & 91 & 65 & 48 \\
\hline Percentage of FDOS & $13 \%$ & $10 \%$ & $7 \%$ & $5 \%$ \\
\hline Total cost of FDOS & $469 €$ & $365 €$ & $260 €$ & $188 €$ \\
\hline Total $\mathrm{CO} 2$ emissions (Kg) from FDOS & 23.7 & 18.4 & 13.2 & 9.2 \\
\hline Percentage of $\mathrm{CO} 2$ emissions from FDOS to total emissions & $9 \%$ & $7 \%$ & $5 \%$ & $4 \%$ \\
\hline
\end{tabular}

\section{Figure 3}

\section{The LDD, a key element for urban pooling}
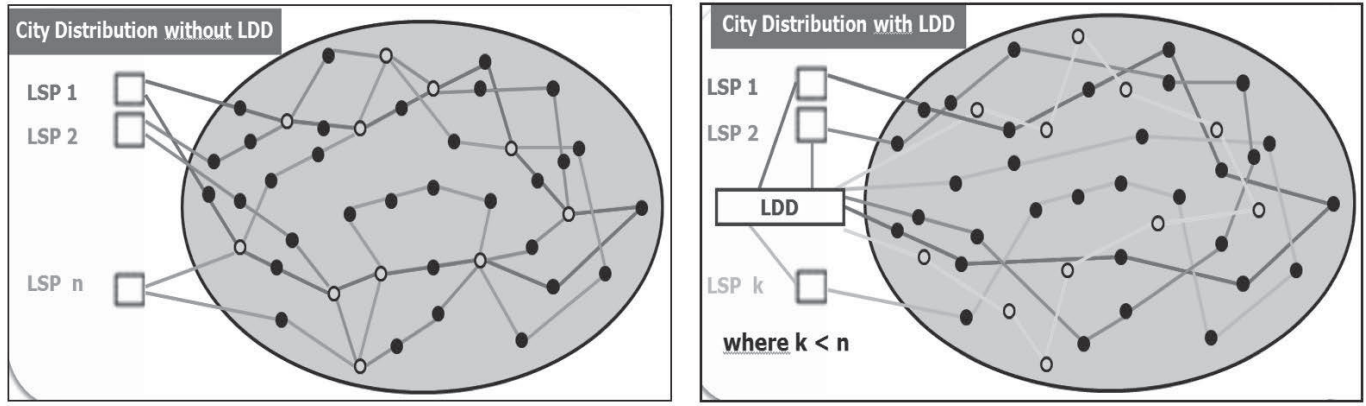

means an improvement in productivity per round (125 parcels delivered on average as opposed to $100)$ as a result of the marked reduction in the number of rounds (17 as opposed to 23). Of course, simply improving the quality of information reduces the failure rate of first deliveries, which in turn leads to an improvement in the performance level of HDs, as Table 3 shows. The four simulations proposed all assume a $25 \%$ use of NPP. Once again, we can see quite a large difference with results halved compared to those found in the first scenario in Table 1.

\section{The scenario of pooling via a local delivery depot}

Cooperation has today become an important topic in interorganisational relationships (Senkel et al., 2013). With initial interest in the synergy created as a result of vertical cooperation between supply chain protagonists, logistics research naturally turned to horizontal relationships, one commonly used expression being load pooling. In the face of various pressures, all those concerned have been obliged to find new strategic means, cooperation being one of these (Pan, 2010). Van Lier et al. (2010) make it clear that this can be carried out effectively "between protagonists on the same level, for example between suppliers, between providers, or between distributors in a supply chain. The introduction of this principle has as its objective the sharing of dedicated set-ups and logistics networks. In other words, it's about doing pooling". Of course, deliveries in dense urban areas are also subject to this current trend for economic and ecological reasons (Fulconis et al., 2011). The role of LSP is particularly emphasized in the management of these generally innovative processes, processes that are given more and more credibility through policies.

Thus, concerning transport of goods in urban areas, a single idea is progressively gaining ground, translated by a true awareness and real development in the thinking process of different protagonists. This idea is delivery pooling, in particular concerning the "last mile". The significant progress in B2C, coupled with the new lease of life in town centres through a revival of local shops, is the reason it has come about. Although retailers in the past have not always been too concerned about deliveries, the expected impact of online retailing requires, henceforth, a completely different attitude. However, there lies a gulf between accepting pooling as a worthy idea and actually putting it into practice operationally.

Within the boundary of the third scenario of development, the e-LSP - mostly parcel service - remains in competition but are looking this time to collaborate over the last few miles. The question is whether online shoppers are prepared to be disturbed at untimely hours in the same evening by several delivery services. Would they not prefer, for example, on a Saturday morning, to do the rounds of several NPP to pick up what they have bought 
online? It is quite clear that if consumers have chosen to buy online to reduce time spent going out to the shops, they are not going to want this additional bother. It therefore seems essential to be able to limit this inconvenience, which otherwise could hinder the development of online retailing as well as increase the congestion in town centres and pollution associated with the increased traffic (Gratadour, 2004). What is necessary, therefore, is to develop solutions that tend towards only "one ring of the doorbell" to minimise disturbance and the number of journeys. This problem of optimising distribution over the last mile raises awareness of the need for areas of pooling through local infrastructure. Fairly moderately sized LDD, around $200 \mathrm{~m} 2$ to $250 \mathrm{~m} 2$, located in the hyper-centre of towns seems to be a good-enough answer (see Figure 3).

Goods ordered online by shoppers living in the town centre can, effectively, be quite easily grouped together in a single LDD to then be "assembled" by the addressee (Dablanc, 1998; Yrjölä, 2003). This then reduces the number of HD and pickup operations (an LDD can double up as an NPP) and reduces the total number of kilometres travelled and the time spent carrying out deliveries, which automatically means a reduction in costs and $\mathrm{CO} 2$ emissions. Pollution is diminished by fewer vehicles on the roads and shorter journeys required by those vehicles (Boudouin \& Morel, 2002). Therefore, as Patier (2002) underlines, the determining factor is the number of freight-handling locations and how well situated they are within the town. It must also be stressed that the success in practice of these operations of consolidation and the efficient processing of parcels imply the availability of a minimum amount of quality information to all operators, in particular through the use of standard directional labelling. Pooling of physical flows requires, as a result, a partial consolidation of informational flows, for example, via a virtual consolidation platform with addresses, contact details, availability, bar code monitoring, and so on to enable the e-LSP responsible for the last mile to be completely successful in the delivery task.

After the first two scenarios, that of 0 -pooling and pooling via NPP, it must be stressed that the third, that of pooling via a LDD, represents a significant break from usual behaviour. It reveals a real willingness to improve performance of distribution to urban online shoppers on a longterm basis. For the upstream journey, notably to the LDD as part of dedicated $\mathrm{B} 2 \mathrm{~B}$ deliveries, all the LSP work independently of their colleagues and competitors, continuing to rely on their own networks. However, on the downstream part of the delivery, which represents the last few kilometres in town, the LSP consolidate their loads. From one or several LDD, they attempt to achieve the "all-in-one" delivery (see Figure 4), that is, the delivery of all parcels in one go or the pickup operation of these same parcels again in one go ("only onestop pickup"). It must be acknowledged that since 2011, the LSP taking on the last-mile deliveries to online shoppers in Nantes hyper-centre have made real progress: "for parcel service delivery, the final kilometres are the most costly and time-consuming. They are the cause of a variety of pollutions and are the least profitable... We should, from now on, think about handing them over to specialists who have the tools to deal with them (fleets of small clean vehicles) and who are capable of pooling, leaving us to get on with what we do best".

In the more specific case of delivery to online shoppers in the hypercentre of Nantes via an LDD (located near Place du Commerce), according to the basic model and using the statistics in Box 2, the total operating cost is calculated at $5,300 €$ net per day. That represents an increase of $24 \%$ compared to the second scenario, which can be explained by the trans-shipment cost imposed for using the LDD and the increased number of delivery rounds (22 as opposed to 17). We should remind




Box 2:

\section{Delivery to online shoppers in Nantes via a LDD}

Each day in Nantes centre about 1,000 parcels are delivered to just over 900 online shoppers at their homes. To enable this, around 10 LSP operate 22 delivery rounds, one fewer than in the 0-pooling scenario (first scenario). The leading "postal" operator still delivers $65 \%$ of total parcels (see Box 1). The other "parcel" or "express" operators deliver their parcels to a central LDD using eight B2B delivery rounds (and not 14 as in the first scenario, when 322 Internet customers had their online orders delivered directly to their homes, at an average of 23 units per delivery round). In the course of these eight rounds $100 \%$ of the parcels are destined for retailers, with an average of 44 deliveries at a rate of six per hour. The LDD represents the 45 delivery addresses where the dropping-off time can be as long as 40 minutes with 40 to 45 parcels being deposited for onward delivery to private customers. The total number of delivery addresses between these two outer scenarios drops from 672 to 360 and is the reason for the marked decrease in the number of delivery rounds, from 14 to 8 . Delivery to the 350 retailers is maintained. A local courier service takes on the last-mile distribution, delivering the 350 parcels destined for online shoppers and in transit through the LDD, using five B2C delivery rounds. For each of these rounds, an average of 64 addresses are delivered to, at a rate of eight per hour.

The average length of a combined "postal" and B2B delivery round is $45 \mathrm{~km}$, as opposed to $5 \mathrm{~km}$ for delivery rounds from the LDD. The daily operating cost of a delivery round remains at $250 €$ net, taking into consideration the daily operating cost of the LDD, which at $100 €$ for rent and $150 €$ for staff represents around 0.70 to $0.75 €$ per parcel. Two-thirds of vehicles used by postal operators are petrol- or diesel-powered utility vehicles, emitting $0.3194 \mathrm{~kg}$ of $\mathrm{CO} 2$ per $\mathrm{km}$. The remaining utility vehicles are electric. As for vehicles used by the parcel and express service operators, $75 \%$ are petrol- or diesel-powered with four 10T trucks and two utility vehicles. In addition, of these eight parcel rounds, two are operated using electric utility vehicles. Finally, the local courier service uses only electric utility vehicles for their five delivery rounds in the hyper-centre of Nantes. There is deemed to be no failure rate of first delivery to retailers, but it is generally above $10 \%$ for online shoppers:

- increasing from $5 \%$ to $14 \%$ for online shoppers delivered by "postal" rounds

- increasing from $13 \%$ to $40 \%$ for online shoppers delivered by local courier service

Table 4

Economic and ecological impacts of failure to deliver first time, with $35 \%$ of deliveries via an LDD

\begin{tabular}{|c|c|c|c|c|}
\hline Rate of failure to deliver 1st time to online shopper & Simul 1 & Simul 2 & Simul 3 & Simul 4 \\
\hline-9 "postal" service rounds & $14 \%$ & $11 \%$ & $8 \%$ & $5 \%$ \\
\hline-5 "online shoppers" service rounds & $40 \%$ & $31 \%$ & $22 \%$ & $13 \%$ \\
\hline \multicolumn{5}{|l|}{ - 8 "retailers \& LDD" service rounds } \\
\hline Total of Failure to Deliver to Online Shoppers (FDOS) & 206 & 163 & 115 & 76 \\
\hline Percentage of FDOS & $23 \%$ & $18 \%$ & $13 \%$ & $8 \%$ \\
\hline Total cost of FDOS & $613 €$ & $485 €$ & $342 €$ & $231 €$ \\
\hline Total $\mathrm{CO} 2$ emissions (Kg) from FDOS & 12.0 & 9.4 & 6.8 & 5.3 \\
\hline Percentage of $\mathrm{CO} 2$ emissions from FDOS to total emissions & $5 \%$ & $4 \%$ & $3 \%$ & $2 \%$ \\
\hline
\end{tabular}

ourselves that in the second scenario, HD is not systematic, unlike in the first and third scenarios. Environmentally speaking, however, pollution increase is less pronounced because of greater use of electric utility vehicles, the daily $\mathrm{CO} 2$ emissions being calculated at just over $220 \mathrm{~kg}$ (i.e. $+3 \%$ ). For our studies based on the third scenario, we of course calculated once more the economic and ecological impacts of the rate of failure to deliver the first time. Table 4 illustrates this with a summary of our findings using the same criteria as in the first two scenarios. It shows there is a real advantage in consolidation through LDD.

\section{Conclusion}

Throughout this article we have concentrated on three key scenarios in urban distribution to online shoppers. In particular we have tried to measure the economic and ecological impacts of the failure to deliver to these customers. The results obtained, through simulations around a control scenario, have permitted us to conclude that the two scenarios in which pooling is present are more efficient than the control scenario, which is void of any form of collaboration. The logistical merits of pooling can, of course, be calculated on several economic and ecological levels. It should be stated that the scenario of pooling via nearby pickup points is by far the least costly. However, it must also be stressed that this method is the least interesting for the online shopper, who has to go out to a collect point to pick up a parcel as a result bearing the cost of the last mile. This, of course, reduces the cost of the delivery to the operator, and, as a result, falsifies to an extent the comparison between scenarios. 


\begin{tabular}{|c|c|c|c|c|}
\hline Rate of failure to deliver 1st time to online shopper & Simul 1 & Simul 2 & Simul 3 & Simul 4 \\
\hline Total of Failure to Deliver to Online Shoppers (FDOS) & 206 & 163 & 115 & 76 \\
\hline \multicolumn{5}{|l|}{ Cost of failure to deliver } \\
\hline "0-pooling" scenario & $937 €$ & $729 €$ & $521 €$ & $344 €$ \\
\hline Scenario of pooling via a LDD & $613 €$ & $485 €$ & $342 €$ & $231 €$ \\
\hline Evolution & $-35 \%$ & $-33 \%$ & $-34 \%$ & $-33 \%$ \\
\hline \multicolumn{5}{|l|}{$\mathrm{CO} 2$ emissions (in $\mathrm{kg}$ ) of failure to deliver } \\
\hline 0-pooling scenario & 51.0 & 39.6 & 28.4 & 18.3 \\
\hline Scenario of pooling via a LDD & 12.0 & 9.4 & 6.8 & 5.3 \\
\hline Evolution & $-76 \%$ & $-76 \%$ & $-76 \%$ & $-71 \%$ \\
\hline
\end{tabular}

However, this distortion disappears when the control scenario and that of pooling via an LDD are compared. In both scenarios online shoppers are all delivered to at home. These deliveries are carried out either through an operator's agency as part of a mixed B2B and $\mathrm{B} 2 \mathrm{C}$ round or indirectly after transit through an LDD on a dedicated B2C delivery round. This scenario of pooling seems to be in every situation the most effective: (1) economically, in that the daily production cost drops from $5,750 €$ to $5,300 €(-8 \%)$ with the transshipment costs taken into consideration, and (2) ecologically, daily $\mathrm{CO} 2$ emissions are reduced from $303 \mathrm{~kg}$ to $223 \mathrm{~kg}(-26 \%)$ as a result of greater use of electric LCV for deliveries to the town hypercentre from an LDD. The same observations can be made if we look at the rate of failure to deliver first time (see Table 5), whether it be cost (down $33 \%$ on average) or CO2 emissions (down $75 \%$ on average).

Concerning this reduction in emissions, it should be clarified that the high level of efficiency achieved is down for two main reasons: (1) greater use of electric vehicles and (2) the fact that the undelivered parcels no longer come back at the end of a delivery round, as they do in the case with the control model of operator agencies situated on average $15 \mathrm{~km}$ out of town. They remain instead at an LDD in the hyper-centre of town to be re-delivered the following day or collected the same day by the customer. It is easy therefore to understand how a "failed to deliver" parcel can now run up 30 fewer kilometres! These different results, of course, give rise to several lines of thought and as many perspectives for further studies. We will reflect on two: the first on the likely development of load pooling for urban deliveries via one or several LDDs (even if this concept is slow to get off the ground, unlike that of the "drive through") and the second, in an attempt to improve information quality, on the preferable standardisation of parcel directional labels in anticipation of the development of $\mathrm{C} 2 \mathrm{C}$.

\section{References}

Boudouin, D., \& Morel, C. (2002). L'optimisation de la circulation des biens et services en ville. Paris: La Documentation Française.

Dablanc, L. (1998). Le transport de marchandises en ville. Paris: Editions Liaisons.

Dufour, J.-G., \& Patier, D. (1997). Les transports de marchandises et la ville. Table Ronde 109. Paris: Conférence Européenne des Ministres des Transports.

Fulconis, F., Paché, G., \& Roveillo, G. (2011). La prestation logistique: origines, enjeux et perspectives. Caen: Editions Management \& Société.

Gratadour, J.-R. (2004). Le défi logistique du commerce électronique. Paris: Rapport du Club Sénat.
Ifop-Generix Group. (2012). Les Français et la livraison des achats sur Internet. Available at http://www.ifop.fr/

Pan, S. (2010). Contribution à la définition et à l'évaluation de la mutualisation de chaînes logistiques pour réduire les émissions de $\mathrm{CO} 2 \mathrm{du}$ transport: application au cas de la grande distribution. Unpublished doctoral dissertation, Ecole Nationale des Mines de Paris.

Patier, D. (2002). La logistique dans la ville. Paris: Celse.

Patier, D. (2009). Les différentes formes de livraison aux particuliers. Paper presented at the Workshop on Supply Chains, Energie et CO2, Paris.

Senkel, M.-P., Durand, B., \& Vo, T. (2013). La mutualisation logistique: entre théories et pratiques. Logistique \& Management, 21(1), 19-30.

Thévenon, J. (2011). Logistique urbaine, scénarii pour le futur. L'Officiel des Transporteurs, 2.590, 26-27.

Van Lier, T., Macharis, C., Caris, A., \& Vrenken, H. (2010). Internal and external co-loading of outbound flows to increase the sustainability of transport: A case study. Proceedings of the 12th WCTR Conference (pp. 193-208), Lisbon.

Yrjölä, H. (2003). Supply chain considerations for electronic grocery shopping. Unpublished doctoral dissertation, Helsinki University of Technology. 


\section{About the authors}

Bruno Durand is assistant professor of supply chain management at the University of Nantes and a member of the Laboratoire d'Economie et de Management de Nantes Atlantique (LEMNA), France. His research fields include urban logistics, e-commerce, and manufacturer-retailer relationships.

Sonia Mahjoub is assistant professor at the Ecole Nationale Vétérinaire, Agroalimentaire et de l'Alimentation of Nantes and member of the ONIRIS team, France. Involved in a number of research projects, she is the author of publications focussed on supply chain optimisation and urban logistics.

Marie-Pascale Senkel is assistant professor of marketing and logistics at the University of Nantes and a member of the Laboratoire d'Economie et de Management de Nantes Atlantique (LEMNA), France. Her research fields include sustainable supply chains, urban logistics, and retail operations management. 